Country v industry factors in equity returns: (When) do non-unit exposures matter?

Lieven De Moor en Piet Sercu

DEPARTMENT OF ACCOUNTANCY, FINANCE AND INSURANCE (AFI) 


\title{
Country $v$ Industry Factors in Equity Returns: (When) do Non-unit Exposures Matter?*
}

\author{
Lieven De Moor ${ }^{\dagger}$ and Piet Sercu ${ }^{\ddagger}$
}

February 21, 2007

\footnotetext{
*An early and wider-ranging precursor paper by the same authors, entitled Country and Sector Effects in International Stock Returns Revisited, appeared as FETEW Research Report AFI0615, KULeuven, 32p. The authors thank Marno Verbeek, Geert Dhaene, Constant Beckers, Stefan Duchateau, Bruno Solnik, Koen Inghelbrecht and seminar participants at the Katholieke Universiteit Leuven, the European University College Brussels, the French Finance Association (Paris, 2005), the Financial Management Association (Stockholm, 2006) and the International Federation of Scholarly Associations of Management (Berlin, 2006) for helpful discussions and valuable comments on earlier drafts of this paper. Lieven De Moor gratefully acknowledges financial support from the Fund for Scientific Research - Flanders (Belgium)

${ }^{\dagger}$ European University College Brussels, Stormstraat 2, B-1000 Brussels, KU Leuven, and Leuven School of Business and Economics, Naamsestraat 69, B-3000; lieven.demoor@econ.kuleuven.be, +32 498616463.
}

${ }^{\ddagger}$ KU Leuven, Leuven School of Business and Economics, Naamsestraat 69, B-3000; piet.sercu@econ.kuleuven.be, +32 16326756. 


\title{
Country $v$ Industry Factors in Equity Returns: (When) do Non-unit Exposures Matter?
}

\begin{abstract}
The Heston-Rouwenhorst (HR) estimates of country and industry factors have been criticised for assuming that each stock has unit exposures to its own country and industry factor. We address this issue analytically and empirically. Our position is that HR are not modeling and estimating a return generating process. Rather, they provide an algorithm for linearly combining pre-defined standard country and sector portfolio returns such that the effects of different sector weights in country indices (and $v v$ ) are taken into account. This is valid in itself, just like it makes sense to compute a valueweighted or equally-weighted market return even when we know that stocks' betas are probably different from unity. In addition, we find that a Fama-MacBeth variant of HR, which does allow for non-unit exposures, produces nearly identical factors as the original version.

Allowing for non-unit exposures does make sense, though, if the purpose is to estimate a stock's return-generating process, for instance in an event study, or if one wishes to study the analog of $\beta_{j}^{2} \operatorname{var}\left(\tilde{r}_{m}\right)$, the variance generated by the market factor in an individual stock, rather than $\operatorname{var}\left(\tilde{r}_{m}\right)$. If this is the purpose, the relative importance of country factors grows, and even more so if one corrects for the effects of estimation error in the exposures. In fact, exposures to industry factors are surprisingly low-about 0.30 instead of over 0.90 for world and country factors.
\end{abstract}

JEL classification: .

Key words: international stock returns, world, country, sector

\section{Introduction}

Should the international-business discipline change its label to "global" or even "intersectoral"? If globalisation were complete, Roll (1992) argues, stock market indices would be different from each other mainly because the weights of various sectors differ across countries. There may be lots of idiosyncratic noise for an individual asset, but given the world market return and the sector factor, there would be little or no commonalities among the stocks from a given country. To test this, Heston and Rouwenhorst (1994) (HR) adopt a variance-analysis model and estimate from each cross-section of monthly returns a world, country and industry factor. Heston and Rouwenhorst find that in terms of variance the country factors dominate, with the world factor coming next and the industry element being a distant third. Subsequent evidence suggests that the industry factor has gained importance, more recently, and by some other measures than HR's it even overtook the country factor around the millennium. ${ }^{1}$ A second

\footnotetext{
${ }^{1}$ See e.g. Baca et al., 2000; Beckers et al., 1996; Campa J. M. and N. Fernandes, 2006; Carrieri F., Errunza V. and S. Sarkissian, 2003; Cavaglia, S., C. Brightman and M. Aked, 2000; Forbes and Chinn, 2004; Griffin and Karolyi, 1998; Isakov and Sonney, 2003; Rouwenhorst, K. G., 1999. Related work includes Beckers et al., 1992;
} 
finding is that the part of plain-vanilla country-index returns that can be traced to differences in sector weights is smallish, and far smaller than the part of sector-index returns that can be traced to differences in country weights.

Whether countries matter more than sectors is, however, not the key issue of this paper. Rather, the question is whether or not HR assume that all exposures are equal to unity (see e.g. Brooks and Del Negro, 2005, 2006), where non-unit exposures matter and where not, and whether they affect the answers in any meaningful way. A correct return-generating process with unconstrained factor sensitivities would definitely make sense in an event study. It would also make sense if the question is whether the contribution of the country factor to the variance of a randomly selected individual asset is larger then the contribution of the sector element: such a contribution would be given by the squared exposure times the factor variance, not the factor variance in itself. But this is not the question being asked in HR: what they are after is what the relative size is of the variances of the factors themselves, and whether international linkages come from a world factor or an industry one. Studying factor return variances themselves makes sense in well-diversified portfolios, where non-unit exposures tend to wash out anyway. More fundamentally, while Brooks and Del Negro want a return-generating process, HR do nothing of that kind. Rather, while they do use regression, they implicitly construct standard country- and sector-index returns in excess of the world average return - all value weighted or equally weighted, depending on the set-up - and then perform linear combinations of these numbers to simultaneously correct for differences in sector weights across countries and for differences in country weights across industries. Thus, while the HR factors are clearly more sophisticated than single-market returns, they have a similar outlook: they are essentially constructed as appropriately weighted averages of individual returns. Computing the market return can obviously be done without reference to beta, ${ }^{2}$ and doing so does not mean that betas are assumed to be unity; and computing market returns should not be confused with estimating a return-generating process for an individual asset.

In the applied part of the paper we show that while exposures are surely not equal to

Brookes, M., 2000; Ehling, P. and S. B. Ramos, 2006; Emiris, M., 2002; Galati and Tsatsaronis, 2003; Gerard et al., 2003; Hardouvelis et al., 2006; Ramos, 2003; Sentana, 2002; Sharaiha et al., 2003, 2004.

${ }^{2}$ The beta referred to is the one in the market model, the regression of a stock's return $\tilde{r}_{j}$ on the marketindex return $\tilde{r}_{m}: \tilde{r}_{j}=\alpha_{j}+\beta_{j} \tilde{r}_{m}+\epsilon_{j}$. The beta is the stocks measure of non-diversifiable risk in the Capital Asset Pricing Model (CAPM), and the residual is the stock's abnormal or unexpected return that is often used in event studies, studies that describe the typical reaction pattern in case of, for instance, a stock split or an earnings announcement. 
unity, factor estimates based on non-unit exposures do nevertheless not differ from HR ones in any meaningful way. If the question is whether the contribution of the country factor to the variance of a randomly selected individual asset is larger than the contribution of the sector element, the HR conclusion is not reversed; rather, we find that the weight of the country element seems to gain importance. In fact, the big surprise is that stocks' exposures to sectorfactor returns are quite small, about 0.3 , against over 0.90 for exposures to world or country factors. This finding must mean that the country-factor corrections destroy a lot of correlation between stock returns and sector effects, which again means that sector effects are pretty weak relative to country effects. Lastly, we show that estimation error in the exposures has only a minimal effect on the answers.

The conceptual analysis of HR and its alternatives is presented in Section 1. Section 2 discusses the empirical work. We conclude in Section 3.

\section{Test Design Issues}

\subsection{What does variance analysis buy us?}

We refer to individual assets by a code $j=1, \ldots, N$. Affiliated with this code list there is a country-code list $K$ whose element $K(j)$ equals the country code for stock $j$, and a sector-code list $I$ whose element $I(j)$ equals the sector or industry code for stock $j$. The return of the stock is generated by four factors: the world factor $\omega$; the factor of the stock's country, $\kappa_{K(j), t}$; the factor of the stock's industrial sector, $\iota_{I(j), t}$; and a purely idiosyncratic risk, $\epsilon_{j, t}$ :

$$
\tilde{r}_{j, t}=\omega_{t}+\kappa_{K(j), t}+\iota_{I(j), t}+\epsilon_{j, t}
$$

The country factors have a weighted mean of zero across countries, and likewise for the industry factors. (We return to the issue of weighting schemes later.) In practice, this analysisof-variance type model is estimated by cross-sectional regressions, one per period $t$, with a constant and two full sets of dummies indicating $j$ 's country or industry affiliation, and with the constraint that the weighted average country or industry effect be zero each period. For simplicity of notation we drop the time subscripts. The country and sector weights are denoted as $w^{c}$ and $w^{i}$. Thus,

$$
\begin{gathered}
\tilde{r}_{j}=\omega+\sum_{k} \kappa_{k} \mathbf{1}_{k=K(j)}+\sum_{i} \iota_{i} \mathbf{1}_{i=I(j)}+\epsilon_{j}, \\
\text { s.t. } \sum_{k} w_{k}^{c} \kappa_{k}=0=\sum_{i} w_{i}^{s} \iota_{i} .
\end{gathered}
$$


These cross-sectional regressions are run every period, thus generating a time series of world, country and industry factors needed for the analysis.

Brooks and Del Negro (2005, 2006) object that, in Equation (1.1), all stocks from a given country are assumed to have equal exposures to the country factor, and likewise in the industry dimension. In defense of the variance-analysis model it could be argued that Equation (1.1) is not really meant to capture the true return-generating process; rather, it is intended as a device that allows one to compute and combine equally- or value-weighted index returns into factors in a simple, transparent way. In fact, it does not even require regression, just linear operations of returns from standard country and sector indices. To see this, start from a model simplified to $r_{j}=\omega+\epsilon_{j}$. Clearly, the OLS estimate that results from a cross-sectional regression on a constant would be the equally weighted world market return; and while one could question whether one should weight equally when constructing a market return, the computation of such a market return in itself does not assume that all stocks have equal market sensitivities. Likewise, if one adds one set of dummies, say the nationality indicators, s.t. a zero-sum constraint, then each OLS-estimated $\kappa_{k}$ becomes the country's equally weighted mean return in excess of the grand mean, which in turn is measured by $\omega$. Again, the mere computation of the equally weighted country returns does not assume that all stocks are equally exposed to that market factor. ${ }^{3}$ Obviously, if there is just a world factor and a set of country factors, we do not really need regression in the first place. Regression seems to become more useful if there are two or more sets of dummies: then the simple country-by-country and industry-by-industry $\omega$-corrected mean returns need to be adjusted for overlaps between the two classifications, which is exactly what a variance analysis model does. Yet in the end even the HR two-dimensional analysis is equivalent to a computation of standard mean returns followed by linear operations based on differences in country weights within indices and of sector weights within countries, as we now show.

Let us define $w_{j}$ to be a set of weights for the stocks in the world market factor. This could be equally weighted, or value weighted, or perhaps even a scheme that gives all sector $\times$ country portfolios an equal weight in the total world factor. We further denote weights for sub-

\footnotetext{
${ }^{3}$ To get weighted indices it would suffice to run weighted LS instead of OLS. But the main point is, familiarly, that regressions on dummies and/or a constant just produce means or operations on means, whether equally weighted or not.
} 
aggregates and sub-index returns as follows:

$$
\begin{aligned}
w_{i, k}^{s c} & =\frac{\sum_{j} w_{j} \mathbf{1}_{i=I(j)} \mathbf{1}_{k=K(j)}}{\sum_{j} w_{j} \mathbf{1}_{k=K(j)}}, \text { the weight of sector } i \text { in the } k \text {-th national market } k, \\
w_{k, i}^{c s} & =\frac{\sum_{j} w_{j} \mathbf{1}_{i=I(j)} \mathbf{1}_{k=K(j)}}{\sum_{j} w_{j} \mathbf{1}_{i=I(j)}}, \text { the weight of country } k \text { in the } i \text {-th sectoral index, } \\
w_{k}^{c}= & \sum_{j} w_{j} \mathbf{1}_{k=K(j)}, \text { the weight of country } k \text { in the world index, } \\
w_{i}^{s}= & \sum_{j} w_{j} \mathbf{1}_{i=I(j)}, \text { the weight of sector } i \text { in the world index, } \\
r_{k}^{c}= & \frac{\sum_{j} w_{j} \mathbf{1}_{k=K(j)} r_{j}}{\sum_{j} w_{j} \mathbf{1}_{k=K(j)}}, \text { the weighted average return of stocks from country } k, \\
r_{i}^{s}= & \frac{\sum_{j} w_{j} \mathbf{1}_{i=I(j)} r_{j}}{\sum_{j} w_{j} \mathbf{1}_{i=I(j)}}, \text { the weighted average return of stocks from sector } i .
\end{aligned}
$$

To interpret the country factor, we start from the standard definition of the country's marketindex return, Equation (1.4), and substitute the HR Equation (1.1), taking into account that all stocks are from the same country. We next take the constants out of the averaging operation and also use the feature that, because of the country dummy, in each national subsample the residuals sum to zero. In the last line but one we use the constraint $\sum_{i} w_{i}^{s} \iota_{i}=0$ so as to facilitate interpretation:

$$
\begin{aligned}
r_{k}^{c} & =\frac{\sum_{j} w_{j} \mathbf{1}_{k=K(j)}\left(\omega+\kappa_{k}+\sum_{i} \iota_{i} \mathbf{1}_{i=I(j)}+\epsilon_{j}\right)}{\sum_{j} w_{j} \mathbf{1}_{k=K(j)}} \\
& =\omega+\kappa_{k}+\sum_{i} \iota_{i} \frac{\sum_{j} \mathbf{1}_{i=I(j)} \mathbf{1}_{k=K(j)}}{\sum_{j} w_{j} \mathbf{1}_{k=K(j)}} \\
& =\omega+\kappa_{k}+\sum_{i} \iota_{i} w_{i . k}^{s c} \\
& =\omega+\kappa_{k}+\sum_{i} \iota_{i}\left(w_{i . k}^{s c}-w_{i}^{s}\right) \\
\Rightarrow \kappa_{k} & =\left(r_{k}^{c}-\omega\right)-\sum_{i}\left(w_{i . k}^{s c}-w_{i}^{s}\right) \iota_{i} .
\end{aligned}
$$

Thus, the country factor implicitly starts from the standard country-index return in excess of the world return $\omega$, and corrects this for industry factors if and to the extent that the country's industry weights $w^{s c}$ differ from the global sector weights $w^{s}$ as used in the world-market factor. A similar result holds for the industry factors:

$$
\iota_{i}=\left(r_{i}^{s}-\omega\right)-\sum_{k}\left(w_{k, i}^{c s}-w_{k}^{c}\right) \kappa_{k}
$$

Thus, regression is not really necessary: given $N^{c}-1$ raw country returns and $N^{s}-1$ raw sector returns in excess of the world-market return, one needs just to solve $N^{c}+N^{s}-2$ of the 
linear equations (1.5) and (1.6), plus two zero-sum constraints, to find the factors. In light of this, a major difference between Brooks and Del Negro on the one hand, and the original design by HR on the other, is that the former are after a data generating process for stock returns, exposures and all, while the latter simply compute factors from equally- or value-weighted country and industry indices, correcting for unusual sector weights in countries an for unusual country weights in sectors. There is no saying which approach is more right than the other, as the objectives are different (and valuable in themselves).

An analogy with the market model may be useful. HR's approach would be like computing the market return, and stopping at that: idiosyncratic risk is diversifiable and differences in betas all cancel out if one holds the market portfolio. Still, for some purposes it would be useful to compute betas too. For instance, if one picks a single stock at random, the uncertainty generated by the market would be measured by $\beta_{j}^{2} \operatorname{var}\left(\tilde{r}_{m}\right)$ not $\operatorname{var}\left(\tilde{r}_{m}\right)$; and for an event study the idiosyncratic factor in a return is likewise best calculated, in principle, after allowing for non-unit betas - or it would surely be best if estimation did not introduce any noise. Similarly, in the multifactor context, there would be an interest in a stock's return-generating process if one has in mind an event study, or if the purpose is to check the relative importance of country and industry factors behind an individual stock's return.

Yet the analogy with the market model is far from perfect. In the market model, the market return is pre-specified while the Brooks-Del Negro model simultaneously estimates the factors and the stocks' exposures to them. One strength of the HR approach is simplicity and transparency. If during the estimation of factors one allows for non-unit exposures, in contrast, then exposures will be one of the determinants of how the factor is constructed, but neither the motivation nor the details of the mechanism that links exposures to the construction of the factor are immediately obvious. In addition, the simultaneous estimation of exposures and factors is possible only after imposing constraints on the exposures, and these need to be verified. Lastly, there is the issue of how much estimation noise is introduced if exposures are estimated rather than postulated to be equal to unity. All this is addressed in the remainder of this paper.

\subsection{Constrained or Confirmatory Factor Analysis v Fama-MacBeth}

The most general linear factor model would be one with unconstrained factors and exposures, with the familiar drawback that the model is not identified; that is, an infinite number of rotations is possible. Brooks and Del Negro solve this by postulating that stock is exposed 
only to its own country and its own industry:

$$
\begin{array}{ll}
r_{j}=\omega \beta_{j}+\sum_{k} \kappa_{k} \gamma_{j, k}+\sum_{i} \iota_{i} \delta_{j, i}+\epsilon_{j} \\
\text { s.t. } \quad \gamma_{j, k}=0 \text { if } k \neq K(j), \text { and unconstrained otherwise, } \\
& \delta_{j, i}=0 \text { if } i \neq I(j), \text { and unconstrained otherwise. }
\end{array}
$$

Brooks and Del Negro provide an EM estimation procedure, and asymptotic properties. The approach is quite similar to Confirmatory Factor Analysis, where one imposes a sufficient number of constraints to pin down the correct rotation and where hypotheses testing becomes possible.

Like many pure factor models this procedure is somewhat of a black box. This becomes more of a problem since the zero restrictions imposed on the coefficients are inevitably not fully valid, and the impact of this simplifying assumption on the estimates is hard to trace. A priori, one would expect firms that are active abroad through trade or investments to be exposed to foreign factors too. In fact, Cai and Warnock (2003) show that some firms do exhibit foreign exposure (besides home-market sensitivity), and that this foreign exposure is related to the firm's foreign/total sales ratio. Another problem is that, in our case, the number of left-handside variables is very large relative to the length of the time series. The rule of thumb in the street is rather the inverse: in confirmatory factor analysis the number of observations is, ideally, ten times the number of variables.

A three-step approach that avoids the zero constraints is the Fama-MacBeth-like (1973) procedure adopted by Marsh and Pfleiderer (1997). Step 1 consists of computing proxies for the factors, for instance HR ones. These provisional estimates are denoted by the primes, in the equation below. In Step 2 one uses these provisionally estimated factor returns to compute sensitivities via time-series OLS with constraints:

$$
\begin{array}{ll}
r_{j, t}= & \omega_{t}^{\prime} \beta_{j}+\sum_{k} \kappa_{k, t}^{\prime} \gamma_{j, k}+\sum_{i} \iota_{i, t}^{\prime} \delta_{j, i}+\epsilon_{j, t}, \\
\text { s.t. } & \gamma_{j, k}=0 \text { if } k \neq K(j), \text { and unconstrained otherwise, } \\
& \delta_{j, i}=0 \text { if } i \neq I(j), \text { and unconstrained otherwise. }
\end{array}
$$

In Step 3 one then uses these estimated sensitivities to re-estimate the factors themselves via cross-sectional regression. The regressors now are $\hat{\beta}_{j}, \hat{\gamma}_{j, k}$ and $\hat{\delta}_{j, i}$ instead of the dummies in Equation (1.2):

$$
r_{j}=\omega \hat{\beta}_{j}+\sum_{k} \kappa_{k} \hat{\gamma}_{j, k}+\sum_{i} \iota_{i} \hat{\delta}_{j, i}+\epsilon_{j}
$$


The three-step procedure does provide a way out of the identification problem of standard (exploratory) factor analysis, but the obvious drawbacks are the inconsistency between the Step-1 and Step-3 factors, and the fact that the third-stage regression in no way takes into account the estimation errors that are brought in in Step 2. We address this in the next section.

For future reference, we note that value- or equally-weighted mean exposure to a factor, computed across all associated equities, is not necessarily close to unity. Such a unit-average property does hold, familiarly, for the market model: the mean beta equals unity. More generally, even in multifactor models this holds as long as a factor is computed as the (weighted) average of the returns from stocks associated with that factor - that is, if the regressors were the country- or sector-index returns $r_{k}^{c}$ and $r_{i}^{s}$ rather than the factors $\kappa$ and $\iota$. But in HR, the average exposure to the country-factor for all stocks from the country is not expected to be equal to unity, because the factor contains not just the country's stock returns but also global sector returns - the corrections for sector-weight discrepancies. The same holds for sector exposures. In fact, for industries the deviation of the average exposure from unity could even be stronger: the industry factor is much more different from a standard average industry-index portfolio return, because the country-effect corrections in sector returns are eight times more important, relatively, than the sector-effect corrections in country returns, as we shall see.

\subsection{Research Design}

If there are systematic differences in exposures across factors, a comparison of equally or valueweighted factor portfolios might not tell us what factors have the biggest impact on stocks. We ask the question whether the ranking on the basis of factor variance (like $\left.\operatorname{var}\left(\kappa_{k}\right)\right)$ is the same as the ranking on the basis of factor-generated variance (like $\gamma_{j, k}^{2} \operatorname{var}\left(\kappa_{k}\right)$, for stock $j$ ). Or more precisely, as the verdict is typically based on a comparison of average variance across all countries or sectors, we work with averages of variances generated by factors. Specifically, we consider the variance generated by the $k$-th country factor to be the average, across all stocks, of $\gamma_{j, k}^{2} \operatorname{var}\left(\kappa_{k}\right)$; from this we then compute the average across all countries. The procedure for industry factors is similar.

Since the estimates of $\beta, \gamma$ and $\delta$ are noisy, a statistic like $\operatorname{var}\left(\beta_{j} r_{m}\right)$ tends to be more inflated the noisier the estimated beta. We address this in two ways. First we alleviate this problem by working with country $\times$ sector portfolio returns - equally or value-weighted - as leftside variables in (1.11), rather than the standard individual-stock returns. As pointed out by Fama and MacBeth (1973), exposure estimates for portfolios suffer less from errors-in-variables 
than do estimates for individual stocks. As a convenient by-product, portfolios also allow us to work with balanced panels without inducing survival bias (although the number of shares in a portfolio does vary over time).

Our second line of defense against estimation-error variance is to correct the cross-asset variance of $\hat{\gamma}_{j, K(j)} \kappa_{K(j)}$ (or its industry counterpart) for the variability that comes from estimation error in the exposures. To see how to correct for this, we relate the variance of $\hat{\gamma}_{j, K(j)} \kappa_{K(j)}$ to its conditional moments given $j$ :

$$
\operatorname{var}\left(\hat{\gamma}_{j, K(j)} \kappa_{K(j)}\right)=\mathrm{E}\left(\operatorname{var}\left(\hat{\gamma}_{j, K(j)} \kappa_{K(j)} \mid j\right)\right)+\mathrm{E}\left(\mathrm{E}\left(\hat{\gamma}_{j, K(j)} \kappa_{K(j)} \mid j\right)-\mathrm{E}\left(\hat{\gamma}_{j, K(j)} \kappa_{K(j)}\right)\right)^{2}
$$

Under standard regression assumptions the second part does not involve any variance of estimation errors, but the first one does. Below, we first decompose the expectation of $\hat{\gamma}_{j, K(j)}^{2} \operatorname{var}\left(\kappa_{K(j)}\right)$ for a given stock $j$, and then compute the expectation across all possible $j$ 's. We focus on the variance of the estimation error, $\nu_{j}$, in $j$ 's exposure, ignoring estimation error in the variance estimators, as standard for large samples. Provided that gamma is estimated without bias, we get

$$
\begin{aligned}
\mathrm{E}\left(\hat{\gamma}_{j}^{2} \operatorname{var}\left(\kappa_{K(j)} \mid j\right) \mid j\right)= & \mathrm{E}\left(\left(\gamma_{j, K(j)}+\nu_{j, K(j)}\right)^{2} \mid j\right) \operatorname{var}\left(\kappa_{K(j)}\right) \\
= & \left(\gamma_{j, K(j)}^{2}+\operatorname{var}\left(\nu_{j, K(j)}\right)\right) \operatorname{var}\left(\kappa_{K(j)}\right) \\
\Rightarrow \mathrm{E}\left(\hat{\gamma}_{j}^{2} \operatorname{var}\left(\kappa_{K(j)} \mid j\right)\right)= & \mathrm{E}\left(\gamma_{j, K(j)}^{2} \operatorname{var}\left(\kappa_{K(j)} \mid j\right)\right)+\mathrm{E}\left(\operatorname{var}\left(\nu_{j, K(j)}\right) \operatorname{var}\left(\kappa_{K(j)}\right)\right) \\
= & \mathrm{E}\left(\gamma_{j, K(j)}^{2} \operatorname{var}\left(\kappa_{K(j)}\right)\right) \\
& +\mathrm{E}\left(\operatorname{var}\left(\nu_{j, K(j)}\right)\right) E\left(\operatorname{var}\left(\kappa_{K(j)}\right)\right)+\operatorname{cov}\left(\operatorname{var}\left(\nu_{j, K(j)}\right), \operatorname{var}\left(\kappa_{K(j)}\right)\right) .
\end{aligned}
$$

The second and third terms on the right-hand side of the last line are the items driven by estimation error and need to be take out. For $\operatorname{var}\left(\nu_{j}\right)$ we take the squared sE of $j$ 's estimated exposure, as computed by the regression routine. So in the correction for noise we take into account the average squared estimation error but also the fact that countries with volatile returns also might have noisier estimates.

In most of the paper we work with equally weighted portfolios and indices $\left(w_{j}=1 / N\right)$, generating country or sector weights that are weighted on a size-of-membership basis. Recall that the left-hand side variables are country $\times$ sector portfolios; so estimation was with WLS, using the number of assets within the portfolio as the weight. Value weighting makes no big difference in the HR estimates, and is questionable in the Fama-MacBeth stage anyway: if the regressors are non-unit exposures rather than indicators or dummies, the final result is no longer a value weighted factor. 


\section{Empirical Results}

\section{$2.1 \quad$ Data}

Our aim is to create an equity database that offers maximal coverage within and across countries, minimal data errors and minimal duplications. Many researchers use Thompson Datastream (TDS) for its coverage in terms of number of markets and number of securities in each market. Ince and Porter (2006), however, document important issues of coverage, classification, and data integrity and find that naive use of TDS data can have a large impact on economic inferences. But they also show that after careful screening of the TDS data, inferences drawn from TDS data are similar to those drawn from CRSP. Based on the filters developed using US TDS data, they provide guidelines for screening international TDS data. The screens we apply to the international TDS data are similar to the guidelines proposed in Ince and Porter (2006) and we go even further for some issues as summarized below. (For details we refer to De Moor (2005)). We use 20 years (from Jan. 1980 till Dec. 1999) of end-of-period monthly dollar returns from TDS for common stocks. On the basis of data availability and coverage within and across regions, we select the following countries: North America (Canada, United States), Latin America (Argentina, Brazil, Chile, Colombia, Mexico, Peru), Japan, Asia-exJapan (China, Hong Kong, India, Indonesia, Malaysia, Philippines, Singapore, South Korea, Taiwan, Thailand), Euro-in countries (Austria, Belgium, Finland, France, Germany, Ireland, Italy, Luxemburg, Netherlands, Portugal, Spain), Euro-out countries (Denmark, Greece, Norway, Sweden, UK), Switzerland, Australasia (Australia, New Zealand) and South-Africa. We extract the data from the TDS Research and Dead lists for each country. We screen for undesired assets and data errors. More specifically we delete dual listings within and across exchanges (e.g. ADRs, GDRs, identical shares), preferred shares, warrants, certificates, shares from the same company but with different voting rights, error shares (e.g. shares with no name, one-day shares), shares that duplicate information on individual companies (e.g. funds, trusts, investment companies, financial holding companies). We next apply screens that eliminate small, illiquid and penny stocks. Penny stocks have a larger probability to contain errors. They are often fallen stocks which are highly speculative and illiquid. Small companies also have limited liquidity, can be subject to high price pressure or price manipulation, and often represent too little value to warrant attention. In practice this means that an end-ofmonth price formation of a stock with a market capitalization smaller than USD 10,000,000 or a monthly trading volume smaller than USD 100,000 or a price smaller than USD 1, are eliminated. Whenever trading volume information is not available, we consider an unchanged 
monthly price (in local currency) as a sign of low trading volume and unreliable price formation for that month and hence both returns based on this price are eliminated. Lastly, we eliminate all stock quotes corresponding to a negative book-to-market value. After applying these automated screens we manually screen for high-return errors. TDS contains some returns that are simply too good to be true and can be very influential for regression results. The few high-return errors that slipped through the automated filters are: (1) decimal-sign shifting; (2) anomalously low first price of a series (probably theoretical or illiquid); (3) high reported return not corresponding to a similar change in the market capitalization, price or to a huge dividend payout; (4) data reported before actual introduction date or after the actual delisting date; (5) obvious typos; (6) wrongly handled equity offerings. All these are treated as missing observations.

\section{$2.2 \quad$ Results}

As a first step we run HR using 21 OECD countries and ten level-3 industries. The detailed results are found in Table 1 . One conclusion is that, with these data, country factors have overwhelmingly more variance than industry factors. This conclusion is not surprising in light of others' results on similar data. It is robust to shifting to level-4 industries instead of level 3, to a G7 sample instead of 21 OECD countries, a sample of 39 emerging and OECD countries, or to value weighting instead of equal weighting; we omit tabulation as this is not the focus of the paper. Note the right skewness in the variances, which is relatively more outspoken for the industry factor. Another familiar finding is that the corrections for sector effects in country returns and vice versa are small, on average, even though they can occasionally be large - see e.g. basic industries. Typically, differences in country weights within sector indices represent 12 to $16 \%$ of the variability of the sector factor, while differences in sector weights within country indices represent less than $2 \%$ of the variability of the country factor,

In Step 2 we then estimate world, country and sector exposures by running OLS timeseries regressions (1.9) using the estimated HR factors from the base case as regressors. These exposures are constrained in the Brooks-Del Negro style: a priori a German steel company, for example, cannot be exposed to another country or industry factor, but the own country and sector exposure coefficients are not set equal to unity. We test the weak hypothesis that, for each portfolio, its country exposure equals its sector exposure, without even asking the question whether this common value could also be the same across portfolios and whether it could be unity. Even this weak null is rejected by a very wide margin $\left(\chi^{2}=3353, p=0.00\right)$. This implies 
Table 1: Country and sector factors from the base-case sample

$$
\tilde{r}_{j}=\omega+\sum_{k} \kappa_{k} \mathbf{1}_{k=K(j)}+\sum_{i} \iota_{i} \mathbf{1}_{i=I(j)}+\epsilon_{j}, \text { s.t. } \sum_{k} w_{k}^{c} \kappa_{k}=0=\sum_{i} w_{i}^{s} \iota_{i} .
$$

\begin{tabular}{|c|c|c|c|c|}
\hline \multicolumn{5}{|c|}{ Panel A: country factors } \\
\hline & $\operatorname{var}(\kappa)$ & $\frac{\operatorname{var}\left(\kappa_{k}\right)}{\operatorname{var}\left(r_{k}^{c}-\omega\right)}$ & $\operatorname{var}\left(\sum_{i} w_{i, k}^{s c} \iota_{i}\right)$ & $\frac{\operatorname{var}\left(\sum_{i} w_{i, k}^{s c} \iota_{i}\right)}{\operatorname{var}\left(r_{k}^{c}-\omega\right)}$ \\
\hline Australia & 18.47 & $100.03 \%$ & 0.84 & $4.52 \%$ \\
\hline Germany & 15.97 & $94.24 \%$ & 0.16 & $0.96 \%$ \\
\hline Belgium & 12.26 & $93.04 \%$ & 0.13 & $0.96 \%$ \\
\hline Canada & 14.87 & $92.60 \%$ & 1.68 & $10.44 \%$ \\
\hline Denmark & 13.95 & $95.63 \%$ & 0.27 & $1.87 \%$ \\
\hline Spain & 20.29 & $96.78 \%$ & 1.04 & $4.96 \%$ \\
\hline Finland & 40.74 & $99.55 \%$ & 0.14 & $0.35 \%$ \\
\hline France & 14.56 & $98.36 \%$ & 0.03 & $0.22 \%$ \\
\hline Greece & 154.08 & $101.26 \%$ & 0.33 & $0.21 \%$ \\
\hline Ireland & 15.01 & $98.63 \%$ & 0.56 & $3.68 \%$ \\
\hline Italy & 37.98 & $104.90 \%$ & 1.03 & $2.84 \%$ \\
\hline Japan & 48.38 & $99.48 \%$ & 0.15 & $0.30 \%$ \\
\hline Netherlands & 14.57 & $105.62 \%$ & 0.13 & $0.95 \%$ \\
\hline Norway & 32.34 & $95.56 \%$ & 0.29 & $0.84 \%$ \\
\hline New Zealand & 31.00 & $98.82 \%$ & 0.53 & $1.70 \%$ \\
\hline Austria & 26.72 & $94.48 \%$ & 0.28 & $0.97 \%$ \\
\hline Portugal & 23.70 & $98.48 \%$ & 0.49 & $2.05 \%$ \\
\hline Sweden & 28.17 & $97.01 \%$ & 0.15 & $0.53 \%$ \\
\hline Switzerland & 12.09 & $93.00 \%$ & 0.29 & $2.22 \%$ \\
\hline U.K. & 12.10 & $102.95 \%$ & 0.05 & $0.41 \%$ \\
\hline U.S. & 9.16 & $97.56 \%$ & 0.05 & $0.52 \%$ \\
\hline Cross-country average & 28.40 & $98.00 \%$ & 0.41 & $1.98 \%$ \\
\hline Median & 18.47 & $97.56 \%$ & 0.28 & $1.96 \%$ \\
\hline \multicolumn{5}{|c|}{ Panel B: sector factors } \\
\hline & $\operatorname{var}(\iota)$ & $\frac{\operatorname{var}(\iota)}{\operatorname{var}\left(r_{i}^{s}-\omega\right)}$ & $\operatorname{var}\left(\sum_{i} w_{k, i}^{c s} \kappa\right)$ & $\frac{\operatorname{var}\left(\sum_{i} w_{k, i}^{c s} \kappa\right)}{\operatorname{var}\left(r_{i}^{s}-\omega\right)}$ \\
\hline Basic Industries & 2.09 & $40.33 \%$ & 2.27 & $43.73 \%$ \\
\hline Cyclical Consumer Good & 2.10 & $83.02 \%$ & 0.68 & $26.90 \%$ \\
\hline Cyclical Services & 1.10 & $103.73 \%$ & 0.17 & $16.28 \%$ \\
\hline General Industries & 1.35 & $90.51 \%$ & 0.43 & $28.76 \%$ \\
\hline Information Technology & 17.97 & $82.10 \%$ & 1.19 & $5.43 \%$ \\
\hline Non-cyclical Consumer & 3.94 & $92.00 \%$ & 0.18 & $4.14 \%$ \\
\hline Non-cyclical Services & 4.75 & $92.20 \%$ & 0.54 & $10.39 \%$ \\
\hline Resources & 26.15 & $99.77 \%$ & 3.54 & $13.50 \%$ \\
\hline Financials & 7.10 & $94.96 \%$ & 0.32 & $4.34 \%$ \\
\hline Utilities & 18.24 & $107.78 \%$ & 1.22 & $7.18 \%$ \\
\hline Cross-sector average & 8.48 & $88.64 \%$ & 1.05 & $16.06 \%$ \\
\hline Median & 4.34 & $92.10 \%$ & 0.61 & $11.95 \%$ \\
\hline
\end{tabular}

Key The base case considers 21 OECD countries, and within each country we go down the list of cap-ranked stocks until we have picked up $80 \%$ of the countrys total market capitalization. Equally weighted Level-3 country $\times$ sector portfolio returns are calculated for every country for the period 1990-1999. For every month, the cross-sectional regression equation (2) is run using WLS with weights equal to the number of stocks generating the sector index at that month. The weighted sum for the country and sector factors is set equal to zero with weights equal to the number of shares in portfolio $(\mathrm{k}, \mathrm{i})$. 
Table 2: Correlations between HR and Fama-MacBeth estimates of factors

\begin{tabular}{lcll|ll}
\multicolumn{5}{c|}{ country factors } & \multicolumn{2}{c}{ industry factors } \\
\hline Australia & 0.986 & Japan & 1.000 & Basic Industries & 0.984 \\
Germany & 0.997 & Netherlands & 0.992 & Cyclical consumer & 0.985 \\
Belgium & 0.991 & Norway & 0.997 & Cyclical Service & 0.994 \\
Canada & 0.991 & New Zealand & 0.982 & General industries & 0.991 \\
Denmark & 0.992 & Austria & 0.994 & Information Techn & 0.999 \\
Spain & 0.988 & Portugal & 0.991 & Non-cyclical consumer & 0.995 \\
Finland & 0.997 & Sweden & 0.996 & Non-cyclical services & 0.994 \\
France & 0.996 & Switzerland & 0.995 & Resources & 0.994 \\
Greece & 0.997 & UK & 0.999 & Financials & 0.996 \\
Ireland & 0.988 & US & 0.999 & Utilities & 0.999 \\
Italy & 0.998 & & & & \\
\hline
\end{tabular}

General average: 0.994

Key For the F-MB factor estimation we first regress asset returns on HR factor returns to estimate non-unit exposures, and then we regress returns on exposures re re-estimate the factors. The table shows the correlations between the first- and third-round estimates.

that the "own" exposures are not all equal to unity, which in turn means that $(i)$ a secondstage re-estimation will produce different factors and $(i i)$ the ratio $\operatorname{var}(\gamma \kappa) / \operatorname{var}(\delta \iota)$ will differ from the ratio $\operatorname{var}(\kappa) / \operatorname{var}(\iota)$. The question just is whether the differences are economically meaningful.

In Step 3 we address the first issue, by re-estimating the factors in Fama-MacBeth style.

Figure 1: Country and Industry factor variances: HR v Fama-MacBeth

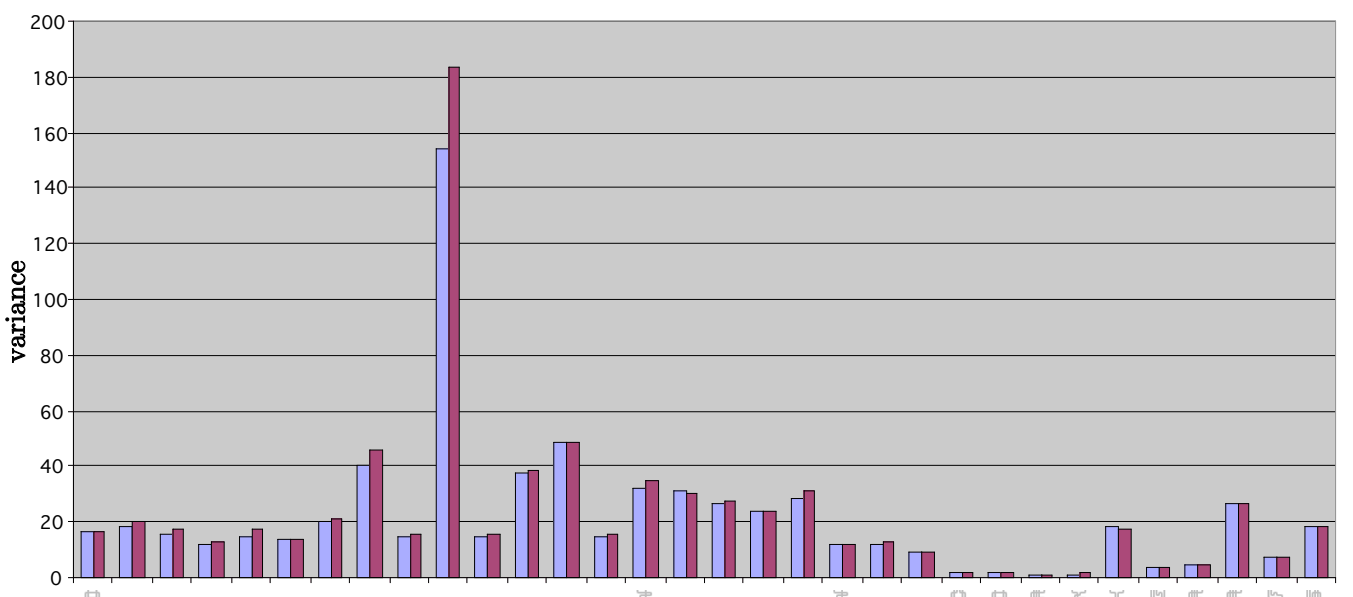

$\square$ Heston-Rouwenhorst $\square$ Fama-McBeth

Key For the F-MB factor estimation we first regress asset returns on HR factor returns to estimate non-unit exposures, and then we regress returns on exposures re re-estimate the factors. The graph shows the variances of the first- and second-round factor estimates. 
Table 3: The Effect of non-unit exposures on variances

\begin{tabular}{lrrrr} 
model & $\begin{array}{r}\text { world } \\
\beta^{2} \operatorname{var}(\omega)\end{array}$ & $\begin{array}{r}\text { country } \\
\gamma^{2} \operatorname{var}(\kappa)\end{array}$ & $\delta^{2} \operatorname{var}(\iota)$ & $\frac{\gamma^{2} \operatorname{var}(\kappa)}{\delta^{2} \operatorname{var}(\iota)}$ \\
\hline HR, $\beta=\gamma=\delta=1$ & 16.50 & 30.54 & 8.32 & 3.67 \\
F-McB factors $\times$ exposures & 16.18 & 25.48 & 2.95 & 8.63 \\
id., corrected for estimation error & 14.85 & 24.36 & 2.23 & 10.92
\end{tabular}

Key Exposures to world $(\beta)$, country $(\gamma)$ and sector $(\delta)$ are obtained by regressing equally-weighted country $\times$ sector portfolio returns on the HR factors $\omega$ (world), $\kappa_{K(j)}$ and $\delta_{L(j)}$. The table shows the average variance of exposure $\times$ factor rather than the average variance.

This is similar to the Heston-Rouwenhorst regression except that Step-2's estimated gammas and deltas are used instead of industry and country dummies. It turns out that the third-step factor returns are almost indistinguishable from the original ones. To illustrate this we show the correlations between the first- and third-step estimates for each factor (Table 2), and a plot of the two variances (Figure 1). The match is near perfect. Although there should be an errors-in-variance problem with the estimated exposures that serve as regressors in Step 3, the resulting attenuation bias in the factor estimates seems to be minor; in fact, the number of factor variances that go down balances the number of cases where the Step-3 variance is up (15 downs against 16 ups). We conclude that there is no evidence that factor estimates are meaningfully affected by possible non-unit exposures.

Lastly we modify the question; rather than wondering whether the country factor in itself typically has more variability than the industry one, we ask whether the country factor adds more variance to a typical individual stock than the industry factor; that is, we compare $\operatorname{var}(\gamma \kappa)$ to $\operatorname{var}(\delta \iota)$. We do this in two rounds, first ignoring the estimation error in the exposures, and then correcting for it as outlined above. The factor returns are those from Step 3, the exposures from Step 2. The results are summarized in lines 2 and 3 of Table 3 ; line 1 repeats the HR counterparts, for ease of comparison.

Line 2 in Table 3 offers some surprises: the average Step-1 factor variance is systematically above the mean of exposure squared times variance. This would be unexpected or even impossible in a one-factor market model: because of Jensen's Inequality, the variance of $\beta r_{m}$ is expected to be above the variance of $r_{m}$ itself. Here we see the opposite. The difference is small for the world factor and moderate for the country factor, but very pronounced for the industry part. This could be because the average exposure is low ${ }^{4}$ or because there is a strong

\footnotetext{
${ }^{4}$ Recall, indeed, that since the factors are not weighted averages of the returns from just the associated stocks,
} 
Table 4: Average exposures to world, country and sector factors

\begin{tabular}{lrrrlrrr|lrrr} 
& $\bar{\beta}$ & $\bar{\gamma}$ & $\bar{\delta}$ & $\bar{\beta}$ & $\bar{\gamma}$ & $\bar{\delta}$ & & $\bar{\beta}$ & $\bar{\gamma}$ & $\bar{\delta}$ \\
\hline Australia & 1.06 & 0.94 & 0.13 & Japan & 0.95 & 0.92 & 0.41 & Basic & 0.99 & 1.02 & 0.51 \\
Germany & 0.93 & 0.95 & 0.45 & Netherl & 0.93 & 0.82 & 0.28 & Cyclical Cons & 0.92 & 0.90 & 0.45 \\
Belgium & 1.01 & 1.01 & 0.14 & Norway & 0.98 & 0.85 & 0.24 & Cyclical Serv & 0.93 & 0.97 & 0.17 \\
Canada & 0.94 & 0.71 & 0.48 & New Zeal. & 0.96 & 0.85 & 0.14 & General Ind & 0.96 & 1.00 & 0.14 \\
Denmark & 0.98 & 1.09 & 0.02 & Austria & 1.06 & 0.93 & 0.17 & IT & 1.20 & 1.11 & 0.51 \\
Spain & 0.87 & 0.97 & 0.20 & Portugal & 0.95 & 0.98 & 0.16 & Noncycl Cons & 0.85 & 0.83 & 0.20 \\
Finland & 0.97 & 0.87 & 0.45 & Sweden & 0.98 & 0.90 & 0.46 & Noncycl Serv & 1.01 & 0.72 & 0.18 \\
France & 0.97 & 0.98 & 0.34 & Switzerl. & 0.92 & 0.94 & 0.27 & Resources & 0.88 & 0.79 & 0.37 \\
Greece & 0.73 & 0.83 & -0.06 & UK & 0.92 & 0.89 & 0.50 & Financials & 0.96 & 0.86 & 0.40 \\
Ireland & 0.98 & 0.51 & 0.30 & US & 0.99 & 1.00 & 1.09 & Utilities & 0.83 & 0.75 & 0.26 \\
Italy & 0.92 & 0.90 & 0.39 & avg cntry & 0.95 & 0.90 & 0.31 & avg sector & 0.95 & 0.90 & 0.32 \\
\hline
\end{tabular}

Key Exposures to world $(\beta)$, country $(\gamma)$ and sector $(\delta)$ are obtained by regressing equally-weighted country $\times$ sector portfolio returns on the HR factors $\omega$ (world), $\kappa_{K(j)}$ and $\delta_{L(j)}$. The averages mentioned in the last line are equally weighted across all countries or sectors regardless of the number of stocks in the portfolio.

negative covariance between exposure and factor variance.

The fact behind the puzzling findings of Table 3 seems to be that average sector exposures are low. Table 4 lists the mean sensitivities of country $\times$ sector portfolios; exposures to world and country factors are mildly below unity, but sector exposures are substantially smaller. Thus, not only are industry factor variances way below country-factor ones, but also the stocks' exposures to them are very low - a surprising and not very intuitive finding. We know that the average delta would have been unity if the sector factor had been the simple sector-index return $r_{i}^{s}$. The regressor we use, instead, is the sector-index return corrected for country-factor returns and geographical-weight discrepancies relative to the world market. Our finding that the resulting sector exposures are so low must then mean that the country-factor corrections destroy a lot of correlation between stock returns and sector effects. It again means that sector effects are pretty weak relative to country effects.

The last line of the table shows that the correction for estimation error in the squared exposure does not materially alter the picture.

see Equation (??), there is no reason to expect value- or equally-weighted mean exposures for the associated stocks to be equal to unity. 


\section{Conclusions}

While for some applications it is useful to estimate a return generating process including unrestricted exposures to factors, this is not the purpose of the Heston Rouwenhorst variance analysis algorithm: while it formally uses regression (OLS and WLS), the HR computations can be done using deterministic linear operations on standard word-, country- and sector-index returns and weight discrepancies. In terms of the familiar market-model regression, HR is like computing the market return, not estimating a conditional expected return an a stock. If one nevertheless leaves exposures free, the resulting factor are economically indistinguishible from the HR originals. The exposures are, however, surprisingly low, especially for the sector effect. As a result, the variance generated by the sector, in an individual stock's return, as compared to the variance of industry factor itself, turns out to be an order of magnitude smaller again. In event studies, for instance, industry corrections would have less impact than world or, $a$ fortiori, country factors. There seems to be no good reason, from all this, to relabel the international-business discipline into global or intersectoral business.

\section{References}

Baca, S.P., B.L. Garbe and R.A. Weiss, 2000. The Rise of Sector Effects in Major Equity Markets. Financial Analysts Journal 56, 34-40.

Beckers, S., G. Connor, and R. Curds, 1996. National versus Global Influences on Equity Returns, Financial Analysts Journal, March/April 1996, Vol. 52, No. 2: 31-39

Beckers, S, G. Grinold, A. Rudd, and D. Stefek, 1992. "The relative importance of common factors across the European equity markets," Journal of Banking and Finance, Elsevier, vol. 16(1), pages 75-95, February.

Brookes, M., 2000. European Banking After EMU: The Impact of EMU on Portfolio Management, in Artis, M., A. Weber and E. Hennessey, eds, The Euro: a Challenge and Opportunity for Financial Markets, Routledge

Brooks, R. and M. Del Negro, 2005. Country versus Region Effects in International Stock Returns Source. Journal of portfolio management 31(4), 67-

Brooks, R. and M. Del Negro, 2006. Firm-level Evidence on International Stock market Comovement, Review of Finance 10, 69-98

Cai, F, and F.E. Warnock, 2006, International Diversification at Home and Abroad. NBER Working Paper 12220

Campa J. M. and N. Fernandes, 2006. Sources of Gains from International Portfolio Diversification. Journal of Empirical Finance 13(4-5), 4-5, 417-44

Carrieri F., Errunza V. and S. Sarkissian, 2003. The Dynamics of Geographic versus Sectoral Diversification: A Causal Explanation. Working paper. 
Country v Industry Factors in Equity Returns

Cavaglia, S., C. Brightman and M. Aked, 2000. The Increasing Importance of Industry Effects. Financial Analysts Journal 56, 41-54

De Moor, L., 2005. The structure of international stock returns: size, country and sector effects in capital asset pricing. Ph.D dissertation at the Faculty of Economics and Applied Economics, K.U.Leuven, Belgium. (http://hdl.handle.net/1979/69)

Ehling, P. and S. B. Ramos, 2006. Geographical versus Industrial Diversification: Constraints Matter. Journal of Empirical Finance, 13(4-5), 396-416

Emiris, M., 2002. Measuring Capital Market Integration. Working Paper, BIS, No. 12.

Fama, E.F. and J. MacBeth, 1973. Risk, return and equilibrium: empirical tests, Journal of Political Economy 81(3), 607-636

Forbes, K. J., and M. D. Chinn, 2004, A Decomposition of Global Linkages in Financial Markets Over Time, Review of Economics and Statistics, August 2004, Vol. 86, No. 3, Pages 705-722

Galati, G. and K. Tsatsaronis, 2003. The Impact of the Euro on Europe's Financial Markets. Financial Markets, Institutions and Instruments 12, 165-222

Gerard B., Hillion P. and F de Roon, 2003. International Portfolio Diversification: Industry, Country and Currency Effects Revisited. Working paper.

Griffin, J. M. and G. A. Karolyi, 1998. Another Look at the Role of the Industrial Structure of Markets for International Diversification Strategies, Journal of Financial Economics 50, 351-373

Hardouvelis, G., D. Malliaropulos, D. and R. Priestley, 2006. EMU and Stock Market Integration. Journal of Business, 79(1), 356-392

Heston, S. and G. Rouwenhorst, 1994. Does Industrial Structure Explain the Benefits of International Diversification? Journal of Financial Economics 36, 3-27.

Ince, O., S., Porter, R., B., 2006. Individual equity return data from Thomson Datastream: handle with care!. Journal of Financial Research, Vol. XXIX, No. 4, 463-479.

Isakov D. and F. Sonney, 2004. Are Practitioners Right? On the Relative Importance of Industrial Factors in International Stock Returns. Swiss Journal of Economics and Statistics 140, 355-379

Marsh, T, and P. Pfleiderer, 1997, The Role of Country and Sector Effects in Explaining Global Stock Returns, Working paper, UC Berkeley and Stanford University

Ramos, S.B., 2003. A Model of Geographical and Industrial Diversification. Unpublished Manuscript.

Roll, R., 1992. Industrial Structure and the Comparative Behavior of International Stock Market Indices, The Journal of Finance, Vol. 47, No. 1. (Mar., 1992), pp. 3-41.

Rouwenhorst, K. G., 1999. European Equity Markets and the EMU, Financial Analysts Journal, Vol. 55, No. 3: (1999)57-64

Sentana, E., 2002. Did EMS Reduce the Cost of Capital? Economic Journal 112, 786-809

Sharaiha, Y., E. Ametistova and S. Emrich, 2003. Global Investing (Revisited) - Country versus Sector Effects. Morgan Stanley Quantitative Strategies, August

Sharaiha, Y., E. Lufkin and S. Emrich, 2004. Global Equity and Derivatives Markets. Morgan Stanley Quantitative and Derivatives Strategies, March 